\title{
IR-LASER INDUCED BRANCH CHAIN REACTION OF HYPOFLUORITES WITH HYDROGEN
}

\author{
E. B. ASLANIDI, R. I. ZAINULIN, N. K. KALANDADZE, \\ and J. S. TURISCHEV
}

The Institute of Stable Isotopes, Tbilisi, USSR

(Received 15 October, 1990; in final form 15 March, 1991)

\begin{abstract}
The parameters of chain explosion occurrence in the mixture of $\mathrm{CF}_{3} \mathrm{OF}$ or $\mathrm{CF}_{2}(\mathrm{OF})_{2}$ with hydrogen induced by a pulsed $\mathrm{CO}_{2}$-laser were studied experimentally. The ranges of inflammation for the both cases were obtained. IR-fluorescence spectra associated with the chain explosion were studied. The chemical reactions describing the observed process qualitatively are given assuming the chain energy branching.
\end{abstract}

Among organic hypofluorites trifluoromethylhypofluorite, $\mathrm{CF}_{3} \mathrm{OF}$, and difluoromethylene-bis-hypofluorite, $\mathrm{CF}_{2}(\mathrm{OF})_{2}$, are thermally the msot stable compounds. These substances attract attention due to their fluorination property which compares unfavourably only with that of elementary fluorine. When the mixture of $\mathrm{CF}_{3} \mathrm{OF}$ with $\mathrm{H}_{2}{ }^{1}$ is induced with a pulsed $\mathrm{CO}_{2}$-laser elementary fluorine is extacted which can be used to solve various problems in chemistry and quantum electronics. As paper ${ }^{1}$ shows the above laser-chemical reaction proceeds by the chain mechanism. During the reaction hypofluorite pressure threshold is observed, above which during laser initiation a gas explosion takes place. The explosion was detected by the variation of IR spectrum after a single pulse. The threshold pressure value is $\sim 0.6$ Torr for $\mathrm{CF}_{3} \mathrm{OF}$ in its mixture with $\sim 1.8$ Torr of hydrogen.

In this paper some parameters of the chain explosion occurrence for $\mathrm{CF}_{3} \mathrm{OF}$ and $\mathrm{CF}_{2}(\mathrm{OF})_{2}$ as well as the parameters of IR radiation, accompanying the observed process are studied experimentally.

The gas excitation was achieved with a pulsed $\mathrm{CO}_{2}$-laser having the pulse energy up to $10 \mathrm{~J}$ at pulse frequency $v=931 \mathrm{~cm}^{-1}$ and pulse duration $\sim 200 \mathrm{~ns}$ at its half-height. The studied gas was fed into a stainless steel reactor with windows made of $\mathrm{NaCl}, \mathrm{CaF}_{2}, \mathrm{BaF}_{2}$ (depending on the problem being solved) and sealed with indium and teflon. The basic component content in the initial hypofluorites was not less than $98 \%, \mathrm{~F}_{2}$ and $\mathrm{COF}_{2}$ being the major impurities.

The measurements of the threshold energy density of the exciting $\mathrm{CO}_{2}$-laser were made based on the hydrogen quantity, hypofluorite pressure being 1 Torr. The chain reaction was measured from the IR absorption spectrum change after each pulse using NKC $=29$ spectrophotometer. The results are given in Figures 1 and 2 . The chain reaction dynamics study was performed by type $\Phi C \Gamma-223 \mathrm{~A}$ photoresistor in a type C8-14 oscillograph. The circuit time resolution is $\sim 1 \mu \mathrm{s}$. 


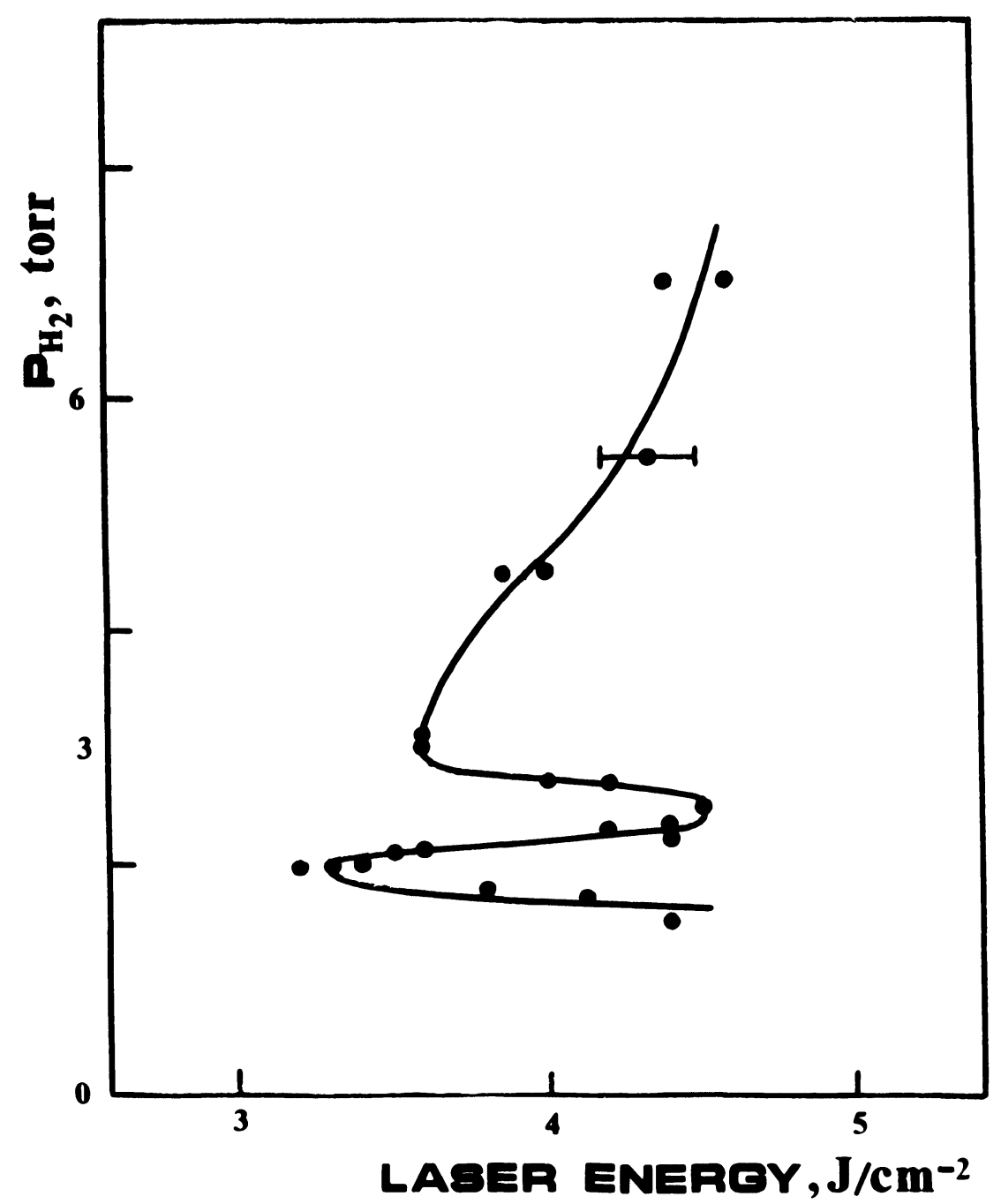

Figure 1 Hydrogen pressure dependence of the threshold laser energy for the chain explosion in the gas mixture $\mathrm{CF}_{3} \mathrm{OF}+\mathrm{H}_{2}\left(\mathrm{P}_{\mathrm{CF}_{3} \mathrm{OF}}=1\right.$ Torr $)$.

Radiation spectra detected by type SPM-2 KBr prism monochromator are given in Figure $3(\mathrm{a}, \mathrm{b})$. Each spectrum contained wave bands with maximums at $2.7 \mu \mathrm{m}$ and $5.5 \mu \mathrm{m}$. When the component ratios of the mixture changed, the intensities of the bands having maximums at 2.7 and $5.5 \mu \mathrm{m}$ changed differently. It confirmed the fact that different compounds are responsible for the fluorescence. The wave band having maximum at $5.5 \mu \mathrm{m}$ can be related to the excited $\mathrm{COF}_{2}$ molecules. IR fluorescence spectrum of $\mathrm{COF}_{2}$ with nitrogen excited in the pulsed gas discharge can prove the fact. The spectrum was measured on the same experimental base. IR and mass spectrum analysis of the final products shows two similar products of laser- 


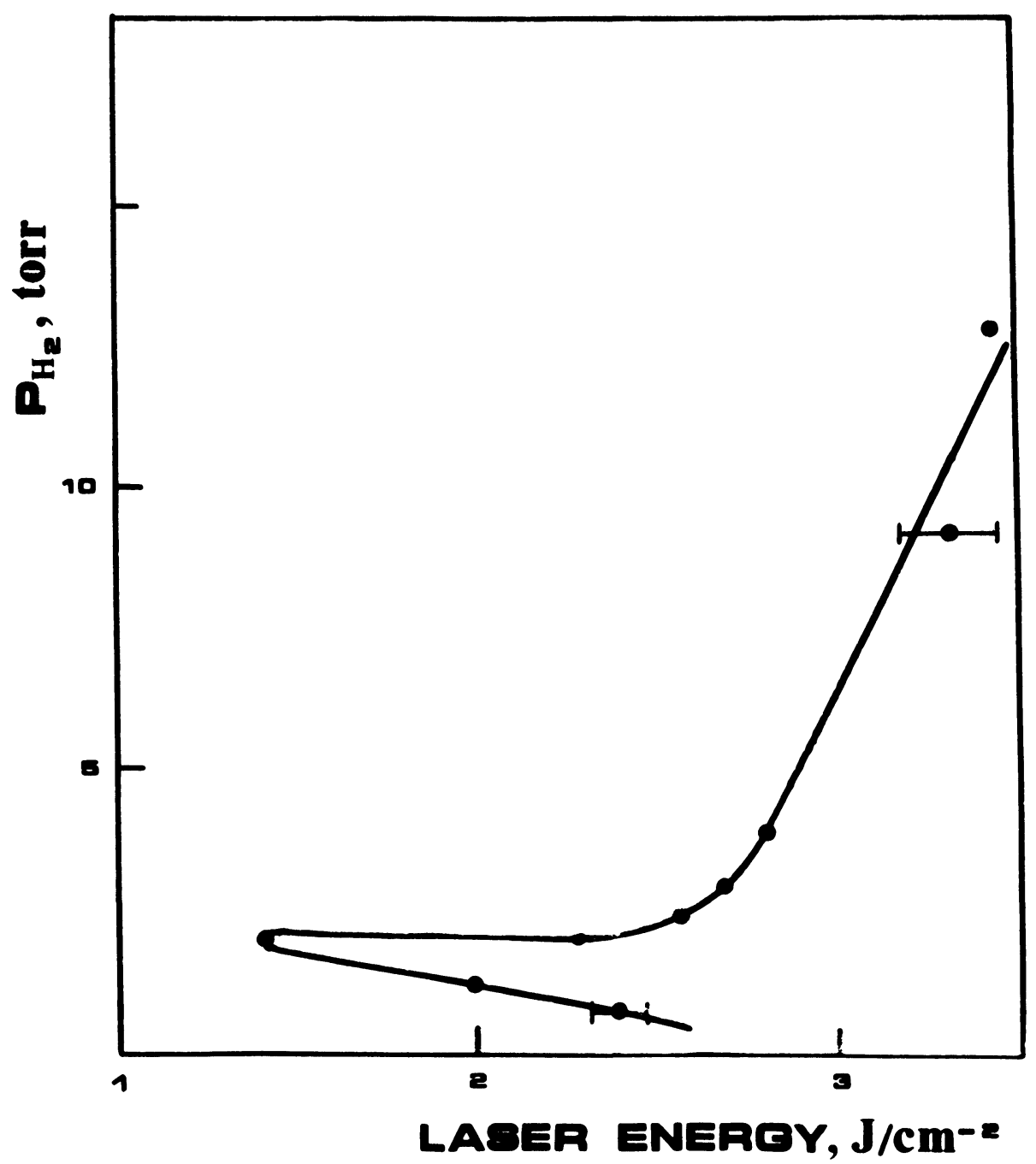

Figure 2 Hydrogen pressure dependence of threshold laser energy density for the chain explosion in the gas mixture $\mathrm{CF}_{2}(\mathrm{OF})_{2}+\mathrm{H}_{2}\left(\mathrm{P}_{\mathrm{CF}_{2}(\mathrm{OF})_{2}}=1\right.$ Torr $)$.

chemistry reaction: $\mathrm{HF}$ and $\mathrm{COF}_{2}$. We cannot expect identical intermediate radicals for these two cases. Radiation similar to that observed at $2.7 \mu \mathrm{m}$ was obtained for the mixture $\mathrm{SF}_{6}: \mathrm{H}_{2}: \mathrm{F}_{2}$ during IR laser excitation. According to ${ }^{2}$ it can be interpreted as $\mathrm{HF}$ fluorescence.

We can conclude from the obtained experimental results that the $\mathrm{CF}_{3} \mathrm{OF}$ or $\mathrm{CF}_{2}(\mathrm{OF})_{2}$ can react in the mixture with hydrogen according to the branched chain mechanism. Inflammation area $^{3}$ observed for the both hypofluorites (see Figures 1 and 2) can be regarded as a proof of the branching.

Based on the results obtained in ${ }^{1.4}$ and on the results obtained in this work we can 


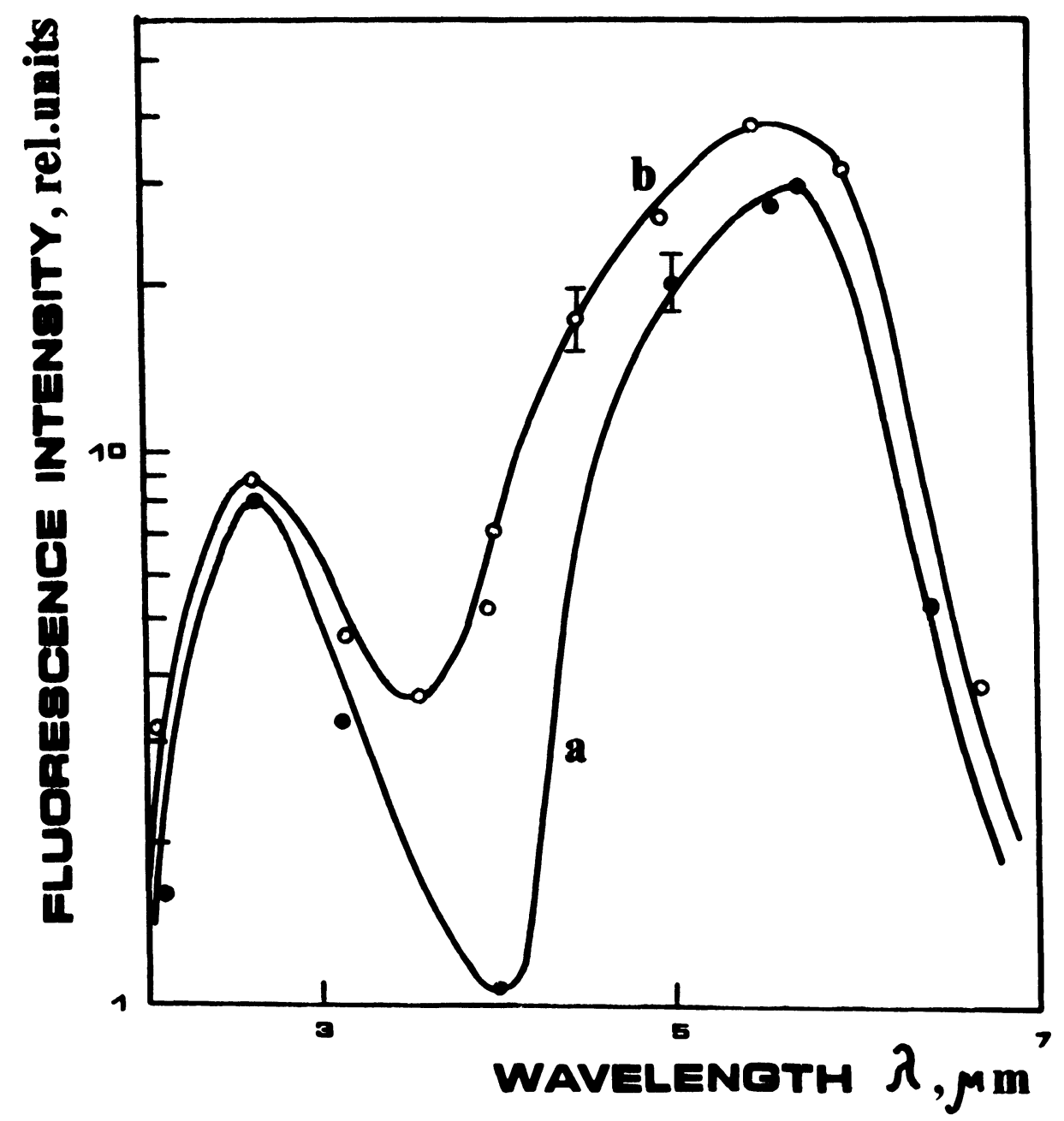

Figure 3 IR spectrum of the mixture (a) $\mathrm{CF}_{3} \mathrm{OF}+\mathrm{H}_{2}$ and (b) $\mathrm{CF}_{2}(\mathrm{OF})_{2}+\mathrm{H}_{2}$ during the chain explosion.

assume energy branching in the chains for trifluoromethylhypofluorite, which permits to write down the reaction succession as follows:

Laser dissociation:

$$
\mathrm{CF}_{3} \mathrm{OF}+n \hbar v \longrightarrow \mathrm{CF}_{3} \mathrm{O}^{\cdot}+\mathrm{F}^{\cdot}
$$

The chain continuation:

$$
-134 \mathrm{~kJ} / \mathrm{mol} \mathrm{F}^{*}+\mathrm{H}_{2} \longrightarrow \mathrm{HF}^{*}+\mathrm{H}^{*}
$$

Chain branching:

$$
\begin{aligned}
& -128 \mathrm{~kJ} / \mathrm{mol} \mathrm{CF}_{3} \mathrm{O}^{\cdot}+\mathrm{H}_{2} \longrightarrow \mathrm{COF}^{2}+\mathrm{HF}^{*}+\mathrm{H}^{*} \\
& -344 \mathrm{~kJ} / \mathrm{mol} \mathrm{H}^{\cdot}+\mathrm{CF}_{3} \mathrm{OF} \longrightarrow \mathrm{CF}_{3} \mathrm{O}^{\cdot}+\mathrm{HF}^{*}
\end{aligned}
$$


Excitation transfer:

$$
\begin{aligned}
\mathrm{COF}_{2}^{*}+\mathrm{CF}_{3} \mathrm{OF} & \rightleftarrows \mathrm{CF}_{3} \mathrm{OF}^{*}+\mathrm{COF}_{2} \\
\mathrm{HF}^{*}+\mathrm{H}_{2} & \rightleftarrows \mathrm{HF}+\mathrm{H}_{2}^{*} \quad \mathrm{H}_{2}^{*}+\mathrm{H}_{2}^{* *} \rightleftarrows \mathrm{H}_{2}^{* *}+\mathrm{H}_{2}
\end{aligned}
$$

Chain branching:

$$
\begin{aligned}
-429 \mathrm{~kJ} / \mathrm{mol} & \mathrm{CF}_{3} \mathrm{OF}^{*}+\mathrm{H}_{2} \longrightarrow \mathrm{COF}_{2}^{*}+2 \mathrm{HF}^{*} \\
& \mathrm{CF}_{3} \mathrm{OF}+\mathrm{H}_{2}^{* *} \longrightarrow \mathrm{COF}_{2}^{*}+2 \mathrm{HF}^{*}
\end{aligned}
$$

Suppression:

$$
\begin{aligned}
\mathrm{CF}_{3} \mathrm{O}^{\circ} \longrightarrow \text { wall } \\
\mathrm{H}^{\cdot} \longrightarrow \text { wall } \\
\mathrm{F}^{\cdot} \longrightarrow \text { wall }
\end{aligned}
$$

Fluorescence:

$$
\begin{gathered}
\mathrm{CF}_{3} \mathrm{O}^{*} \longrightarrow h v_{1}+\mathrm{COF}_{2} \\
\mathrm{HF}^{*} \longrightarrow h v_{2}+\mathrm{HF}
\end{gathered}
$$

The both reactions of excitation must be fast, as almost a resonant energy exchange takes place.

As it is well known the existence of lower inflammation threshold is related with the concurrence of chain branching rate with the chain break rate at the reactor walls. The first rate is directly proportional to the pressure, while the rate of chain break at the wall is kinetically independent of pressure, and diffusionally it increases with the pressure drop. Therefore at rather low pressures chain break rate on the wall will always limit the increase of the number of active centers in the branching reactions.

The existence of the lower threshold can be explained by the concurrence of (2) and (9). When the hydrogen pressure rises the probability of triple collisions of $\mathrm{COF}_{2}^{*}$ and $\mathrm{CF}_{3} \mathrm{OF}^{*}$ rises with the energy loss. The second lower threshold can be explained by reactions (5), (7) and (9).

The addition of fluorine into the reaction mixture adds one additional reaction continuing the chain:

$$
\mathrm{H}^{\cdot}+\mathrm{F}_{2} \longrightarrow \mathrm{HF}^{*}+\mathrm{F}^{*}
$$

Here, as we see from the sequences (1)-(12) the increase of fluorescence intensity should take place for the both molecules.

The performed experiment at the ratio $\mathrm{CF}_{3} \mathrm{OF}: \mathrm{H}_{2}=2$ Torr: 4 Torr showed that the addition of fluorine in the range of 0.2-4 Torr brings about fluorescent band intensity increase with its subsequent suppression. Here the maximum at $2.7 \mu \mathrm{m}$ is reached at fluorine pressure of 1 Torr, and at $5.5 \mu \mathrm{m}$-at fluorine pressure 2.6 Torr. Fluorine prolongs fluorescence from $70 \mu$ s to about $400 \mu \mathrm{s}$. Fluorescent pulse delay from that of the laser pulse prolongs from zero to $300-350 \mu \mathrm{s}$.

Based on the experimental results the sequence of the laser-chemical reactions of difluoromethylene-bis-hypofluorite with hydrogen can be written as follows:

Laser dissociation:

$$
\mathrm{CF}_{2}(\mathrm{OF})_{2}+n \hbar v \longrightarrow \mathrm{CF}_{2} \mathrm{O}_{2}^{\circ}+2 \mathrm{~F}^{\cdot}
$$


Chain branching:

$$
\begin{aligned}
\mathrm{CF}_{2} \mathrm{O}_{2}+\mathrm{H}_{2} & \longrightarrow \mathrm{COF}_{2}^{*}+\mathrm{OH}^{*}+\mathrm{G}^{\cdot} \\
\mathrm{CF}_{2}(\mathrm{OF})_{2}+\mathrm{H}^{\cdot} & \longrightarrow \mathrm{CF}_{2} \mathrm{O}_{2}^{\cdot}+\mathrm{HF}^{*}+\mathrm{F}^{\cdot}
\end{aligned}
$$

Chain continuation:

$$
\begin{aligned}
\mathrm{H}_{2}+\mathrm{OH}^{*} & \longrightarrow \mathrm{H}_{2} \mathrm{O}+\mathrm{H}^{\circ} \\
\mathrm{F}^{\cdot}+\mathrm{H}_{2} & \longrightarrow \mathrm{HF}^{*}+\mathrm{H}^{\circ}
\end{aligned}
$$

Excitation transfer:

$$
\begin{aligned}
& \mathrm{HF}^{*}+\mathrm{H}_{2} \rightleftarrows \mathrm{H}_{2}^{*}+\mathrm{HF} ; \quad \mathrm{H}_{2}^{*}+\mathrm{H}_{2}^{*} \rightleftarrows \mathrm{H}_{2}^{* *}+\mathrm{H}_{2} \\
& \mathrm{COF}_{2}^{*}+\mathrm{CF}_{2}(\mathrm{OF})_{2} \rightleftarrows \mathrm{CF}_{2}(\mathrm{OF})_{2}^{*}+\mathrm{COF}_{2} \\
& {\left[\mathrm{CF}_{2}(\mathrm{OF})_{2}\right] \mathrm{CF}_{2}(\mathrm{OF})_{2}^{*}+\mathrm{H}_{2}\left(\mathrm{H}_{2}^{* *}\right) \longrightarrow \mathrm{CF}_{2} \mathrm{O}_{2}+2 \mathrm{HF}^{*} }
\end{aligned}
$$

Suppression:

$$
\begin{aligned}
\mathrm{CF}_{2} \mathrm{O}_{2} & \longrightarrow \text { wall } \\
\mathrm{F}^{\cdot} \longrightarrow \text { wall } & \longrightarrow \text { wall }
\end{aligned}
$$

Fluorescence:

$$
\begin{gathered}
\mathrm{COF}_{2}^{*} \longrightarrow n \hbar v_{1}+\mathrm{COF}_{2} \\
\mathrm{HF}^{*} \longrightarrow n \hbar v_{2}+\mathrm{HF}
\end{gathered}
$$

The total rate of the reactions (26)-(14) is higher than that for $\mathrm{CF}_{3} \mathrm{OF}+\mathrm{H}_{2}$ mixture, as the fluorescent pulse increase edge for $\mathrm{CF}_{2}(\mathrm{OF})_{2}$ is almost an order of magnitude shorter under the identical experimental conditions. When fluorine was added into the mixture of $\mathrm{CF}_{2}(\mathrm{OF})_{2}$ with $\mathrm{H}_{2}$ the observed dependencies of fluorescent spectrum change vere similar to the above pattern for $\mathrm{CF}_{3} \mathrm{OF}$.

In conclusion we sho ald note that the obtained experimental results are not explained totally in the range of the given chemical equations. The suggested reaction sequences provide only qualitative description of the laser-chemical processes, assuming energy branching of chains. The obtained results of IR-fluorescence measurements hold the promise for the application of these hypofluorites for chemical laser development.

\section{References}

1. E. B. Aslanidi, V. T. Zarubin, A. G. Kudziev and J. S. Turischev, Khimitcheskaya Fizika (Russian), 5(44), 474-478 (1986).

2. John L. Lyman and Reed J. Jensen, J. Phys. Chem. 77(7), 883-888 (1973).

3. N. N. Semenov, Chain Reactions (Nauka, Moscow, 1986).

4. E. B. Aslanidi, N. P. Aslanidi, V. T. Zarubin, R. I. Zainulin, J. S. Turischev, Zhurnal Prikladnoi Spektroskopii (Journ. Appl. Spectr., Russian), 45(5), 785-790 (1986). 